\title{
Produk Interior Modular Berbasis Budaya Nusantara dengan Memanfaatkan Materila Rotan untuk Cafe
}

\author{
Onesimus Bonar Naibaho', Andereas Pandu Setiawan ${ }^{2}$ \\ ${ }^{1}$ Program Studi Desain Interior, Universitas Kristen Petra \\ 1, onesnaibaho2@gmail.com
}

\begin{abstract}
ABSTRAK
Semakin meningkatnya pertumbuhan penduduk di dunia, maka semakin banyak produk yang di butuhkan untuk menjalani hari. Kayu merupakan material yang paling banyak dipakai untuk membuat sebuah produk. Dari waktu ke waktu penggunaan material ini menjadi berlebihan dan berujung pada kerusakan lingkungan, hal ini dikarenakan pengolahan hutan yang buruk menjadikan ekologi hutan dan alam terganggu. Maka dari itu melalui produk ini saya mengajak masyarakat beralih untuk memanfaatkan rotan di mana rotan sendiri memiliki banyak keunggulan seperti lebih ekonomis dan mudah dibentuk. Rotan merupakan material yang mudah didapat khususnya di Indonesia, hal itu adalah wajar karena indonesia sendiri merupakan penghasil rotan terbesar di dunia. Produk yang akan didesain yaitu satu set furnitur yang akan di tempatkan pada interior sebuah cafe, hal ini dipertimbangkan dengan perkembangan trend cafe yang terus meningkat maka saya melihat adanya peluang yang baik untuk membuat produk interior untuk cafe. Desain produk menggunakan desain modular yang merupakan sebuah rancangan desain yang terdiri atas beberapa modul terpisah yang dapat dengan mudah dibongkar pasang serta di konfigurasi. Tidak lupa akan konsep Budaya Nusantara yang ingin ditekankan pada produk ini, di mana budaya lokal seringkali dianggap sebelah mata dan tidak keren sehingga kurang disegani. Melalui produk ini diharapkan dapat menginspirasi masyarakat bahwa konsep Budaya Nusantara juga bisa keren dan bersaing, baik secara estetika yang unik/indah, maupun secara fungsi.
\end{abstract}

Kata kunci: Rotan, Modul, Komersial

\section{ABSTRACT}

The increasing population growth in the world, the more products needed to get through the day. Wood is the material most widely used to make a product. From time to time the use of this material becomes excessive and leads to environmental damage, this is because poor forest processing has disturbed the ecology of the forest and nature. Therefore, through this product, I invite people to switch to utilizing rattan where rattan itself has many advantages such as being more economical and easy to shape. Rattan is a material that is easily available, especially in Indonesia, it is natural because Indonesia itself is the largest producer of rattan in the world. The product to be designed is a set of furnitur that will be placed in the interior of a cafe. This is considered by the increasing trend of cafe developments, so I see a good opportunity to make interior products for cafes. The product design uses a modular design which is a design that consists of several separate modules that can be easily assembled and configured. Do not forget the concept of Nusantara Culture that you want to emphasize in this product, where local culture is often underestimated and uncool so that it is less respected. Through this product, it is hoped that it can inspire the public that the concept of Nusantara Culture can also be cool and competitive, both aesthetically which is unique / beautiful, as well as functionally.

Keywords: Rattan, Modular, Commercial 


\section{PENDAHULUAN}

\section{A. Identifikasi Masalah}

Rotan adalah tanaman yang berasal dari hutan yang sering ditemui di hutan Indonesia. Nama rota (lepidocaryodidae) berasal dari bahasa melayu yang mempunyai arti sekumpulan jenis tanaman family palmae yang tumbuhnya memanjat. Rotan merupakan sebuah bahan material dari alam yang mempunyai peluang besar untuk di manfaatkan. Hal ini di karenakan pertumbuhannya yang sangat banyak di hutan terutama di hutan indonesia. Indonesia sendiri merupakan salah satu negara terbesar penghasil rotan terbesar di dunia. Namun penggunaannya di Indonesia masih kalah bersaing dengan bahan kayu, yang merupakan masalah dunia saat ini di karenakan berkurangnya luas hutan akibat ulah penebangan hutan yang tidak teratur. Organisasi Jaringan Pemantau Hutan Independen, Forest Watch Indonesia (FWI) menyatakan angka laju deforestasi atau penebangan hutan selama 2013 hingga 2017 mencapai 1,47 juta hektare per tahunnya. Angka ini meningkat jika dibandingkan dengan periode 2009 hingga 2013 yang hanya sebesar 1,1 juta hektare per tahun. Indonesia memang terkenal dengan industri berbahan kayu yang bahkan kepopulerannya telah sampai ke tingkat dunia. Namun sayangnya bahan kayu tersebut diambil dari hutan tanpa memperhatikan kelestariannya sehingga banyak hutan yang habis ditebangi dan mulai gundul. Akibatnya, hutan menjadi gersang dan kehilangan fungsinya. Pemerintah telah melakukan beberapa aturan serta undang-undang tentang penebangan pohon sebagai tindakan mencegah semakin bertambah kasus penebangan pohon liar, hal ini membuat membuat penurunan angka penebangan liar, namun tetap kurang dapat menyelesaikan masalah hutan yang sudah terlanjur rusak karena oknum yang tidak bertanggung jawab. Pemerintah juga telah membuat kegiatan penanaman ulang namun hal ini memerlukan bertahun-tahun untuk dapat memulihkan hutan seperti sedia kala. Maka dari itu solusi yang di perlukan yaitu menyadarkan masyarakat untuk meminimalisir penggunaan kayu dan mulai memanfaatkan material ramah lingkungan seperti rotan. Melalui rancangan produk ini diharapkan pengguna dapat menggunakan produk sesuai kebutuhan serta mendapat kenyamanan dan menjadi inspirasi material bagi pengguna.

Semakin berkembangnya bangunan komersial yaitu cafe di kota-kota besar, maka semakin banyak juga kebutuhan produk untuk interior sebuah cafe. Yang paling sering di butuhkan sebuah cafe adalah produk set meja dan kursi, karena cafe merupakan sebuah tempat santai/ bertemu antara pengunjung. Namun material produk yang di pakai di pasaran kebanyakan adalah material kayu dan plastik. Kedua material merupakan material yang tidak ramah lingkungan. Begitupun desain produk yang kaku dan umum di cafe-cafe membuat pengunjung kurang tertarik untuk mengunjungi cafe .

Kebudayaan nusantara merupakan kebudayaan yang di akui sebagai identitas nasional nusantara dan sebagai perwujudan cipta, karya dan karsa bangsa indonesia, penulis memiliki ide untuk mengembangkan sebuah material ramah lingkungan yaitu rotan, menjadi sebuah produk meja dan kursi set dengan memanfaatkan desain modular sehingga lebih efisien serta tidak kaku, ditambah dengan sebuah konsep budaya nusantara yang tentunya menjadi ketertarikan tersendiri.

\section{B. Rumusan Masalah}

Berdasarkan identifikasi masalah dirumuskan masalah penelitian sebagai berikut: bagaimana menghasilkan desain meja kursi set berbahan rotan untuk interior cafe dengan konsep modular dan budaya nusantara?

\section{Tujuan Penelitian}

Tujuan penelitian ini menghasilkan desain meja kursi set rotan yang fungsional dan estetik lewat konsep budaya nusantara di dalamnya. Selain itu memberikan inspirasi pada pengrajin 
rotan dan masyarakat bahwa material ini juga dpat bersaing dengan bahan material lainnya seperti kayu.

\section{Batasan Perancangan}

Batasan perancangan yaitu bagaimana mendesain sebuah perabot set meja kursi yang hemat tempat dimana trend café pada masa ini. Hal ini yang membuat penulis memiliki ide untuk membuat konsep modular agar produk dapat disesuikan pada bentuk ruangan nantinya.

\section{METODE PENELITIAN}

Penelitian ini menggunakan metode perancangan Design Thinking. Proses Design Thinking terbagi menjadi 6 bagian yaitu understand, observe, frame and reframe, ideate, prototype, test.

\section{A. Understand}

Pemahaman dan pengumpulan data mengenal bahan rotan dan budaya yang akan diangkat sebagai ide perancangan produk. Dilakukan dengan cara membaca literatur dan browsing mengenai data terkait.

\section{B. Observe}

Mengenal perlakuan rotan di lapangan secara langsung sehingga dapat memahami karakter dan perlakuan terhadap bahan rotan sebelum dimanfaatkan.

\section{Frame and Reframe}

Proses melakukan mindmap dan brainstorming dari semua data yang telah didapatkan agar dapat memetakan ide perancangan sesuai dengan data yang ada.

\section{Ideate}

Proses pemunculan ide sesuai dengan data yang telah dipetakan sehingga menghasilkan konsep yang sesuai dengan apa yang ingin dicapai.

\section{E. Prototype}

Proses membuat gambar kerja dan pembuatan prototipe 1:1 untuk nantinya dites dan hasilnya akan dimasukkan ke dalam laporan.

\section{F. Test}

Melakukan pengujian terhadap prototipe 1:1 yang telah direalisasikan, selain itu melakuakn presentasi desain dan evaluasi, serta respon public sebagai masukan desain.

\section{STUDI LITERATUR}

\section{A. Produk Interior}

Produk interior atau furnitur adalah istilah yang digunakan untuk perabot rumah tangga yang berfungsi sebagai tempat penyimpan barang, tempat duduk, tempat tidur, tempat mengerjakan sesuatu dalam bentuk meja atau tempat menaruh barang di permukaannya. Misalnya furnitur sebagai tempat penyimpan biasanya dilengkapi dengan pintu, laci dan rak, contoh lemari pakaian, lemari buku dll. Furnitur berasal dari bahasa Prancis adalah fourniture (1520-30 Masehi). Furnitur mempunyai asal kata fournir yang artinya furnish atau perabot rumah atau ruangan. Walaupun mebel dan furnitur punya arti yang beda, tetapi yang ditunjuk sama yaitu meja, kursi, lemari, dan seterusnya. Furnitur dapat terbuat dari kayu, bambu, logam, plastik dan lain sebagainya. Furnitur sebagai produk artistik biasanya terbuat dari kayu pilihan dengan warna dan tekstur indah yang dikerjakan dengan penyelesaian akhir yang halus. Dengan menyajikan furnitur yang tepat, maka rumah anda akan makin indah dan menarik. Dengan furnitur, anda dapat mengekspresikan interior rumah yang sesuai dengan gaya dan kepribadian anda, karena furnitur adalah modal utama dalam penentuan interior rumah.

\section{B. Desain Modular}

Pendekatan yang membagi sistem menjadi bagian-bagian kecil (modul) yang dapat mandiri dibuat dan kemudian digunakan dalam sistem yang berbeda untuk mengarahkan beberapa 
fungsi. Gagasan pokok modular desain adalah untuk mengembangkan serangkaian komponenkomponen produk dasar yang dapat dirakit menjadi sejumlah besar produk yang berbeda-beda. Desain modular dengan bagian yang terpisah-pisah, memungkinkan perusahaan untuk melakukan reparasi, pemeliharaan atau penggantian salah satu modul atau komponen yang rusak. Sebuah sistem modular dapat dicirikan sebagai berikut:

- Fungsional partisi ke diskrit terukur, modul dapat digunakan kembali yang terdiri dari terisolasi, mandiri elemen fungsional

- Ketat menggunakan antar muka yang terdefinisi dengan baik modular, termasuk berorientasi objek deskripsi fungsi modul

Kemudahan perubahan untuk mencapai transparansi teknologi dan, sejauh mungkin, menggunakan standar industri untuk antar muka utama. Selain pengurangan biaya (karena kustomisasi yang lebih rendah, dan waktu belajarkurang), dan fleksibilitas dalam desain, modularitas menawarkan manfaat lain sepertiaugmentasi (menambah solusi baru hanya dengan cara menghubungkannya dengan modul baru.

\section{Bangunan Komersial}

Pengertian bangunan komersial yaitu bangunan yang sengaja didirikan untuk menghasilkan keuntungan dari aktivitas komersial bangunan tersebut bagi pemiliknya. Definisi aktivitas komersial adalah kegiatan-kegiatan yang berhubungan langsung dengan jual, beli, dan sewa. Jadi bangunan komersial merupakan bangunan yang dijual kembali ke pembeli atau disewakan selama periode waktu tertentu.

Seseorang yang menyewa atau membeli bangunan komersial umumnya akan menjual barang dan atau jasa. Contoh bangunan komersial yang digunakan untuk menjual barang antara lain kios, ruko, supermarket, mall, pasar, dan restoran. Sedangkan bangunan komersial yang dipakai untuk menjual jasa misalnya laundry, hotel, dan perkantoran

\section{Ergonomi dan Antopometri}

Arti kata antropometri berasal dari bahasa Yunani yaitu "anthropos" (manusia) dan "metron" (ukuran). Secara umum dijelaskan, antropometri adalah suatu studi yang sangat berhubungan dengan pengukuran dimensi tubuh manusia. Dan ilmu antropometri sendiri merupakan bagian dari ilmu ergonomi yang khusus dalam mempelajari ukuran tubuh. Sejarah antropometri sudah ada sejak tahun 1987, dimana pada saat itu telah dijelaskan oleh Sanders \& Mc Cormick (1987) antropometri adalah pengukuran dimensi tubuh atau karakteristik fisik tubuh lainnya yang relevan dengan desain tentang sesuatu yang dipakai orang. Antropometri pada umumnya digunakan untuk mempertimbangkan ergonomi atau tidaknya perancangan produk ataupun sistem kerja. Aplikasi antropometri sendiri telah lama digunakan manusia untuk bahan pengkajian produk supaya produk tetap memegang prinsip ergonomis dalam desain maupun sistem kerja. 
E. Tipologi

- Furniture set 1

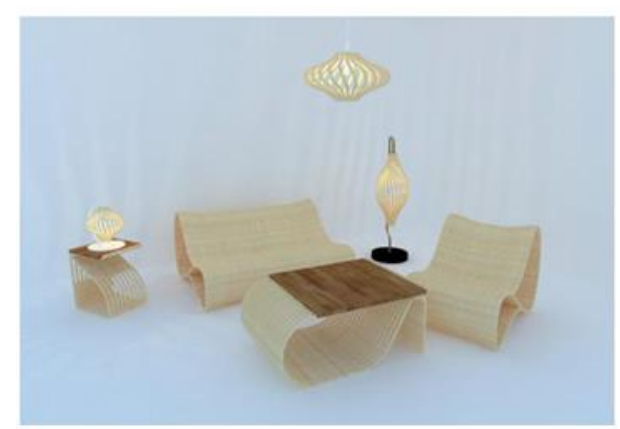

Konsep utama perancangan produk adalah simple-rounded. Simple merujuk kepada selera pasar yakni gaya modern. Sedangkan rounded dipilih untuk mengangkat kelebihan material rotan alami yakni bersifat lentur atau mudah dilengkungkan. Konsep tersebut tidak lepas dari karakteristik alami yang disuguhkan melalui finishing natural, sesuai permintaan pasar, pada material rotan alami yang digunakan. Karakteristik tersebut didukung dengan tipologi bentuk organis/natural yang digunakan dalam mengolah desain produk. Pengaplikasian bahan rotan dalam furnitur set ini sudah baik, akan tetapi penggunaan bentuk dan fungsi kurang di maksimalkan. Produk hanya memiliki 1 fungsi dan bentukan furnitur dapat memakan banyak space. Dimana pada masa ini furnitur set yang dapat meminimalisir space sangat di butuhkan masyarakat. Jadi apabila ada konsep modular, akan dapat memaksimalkan furnitur set ini

- $\quad$ Furniture set 2

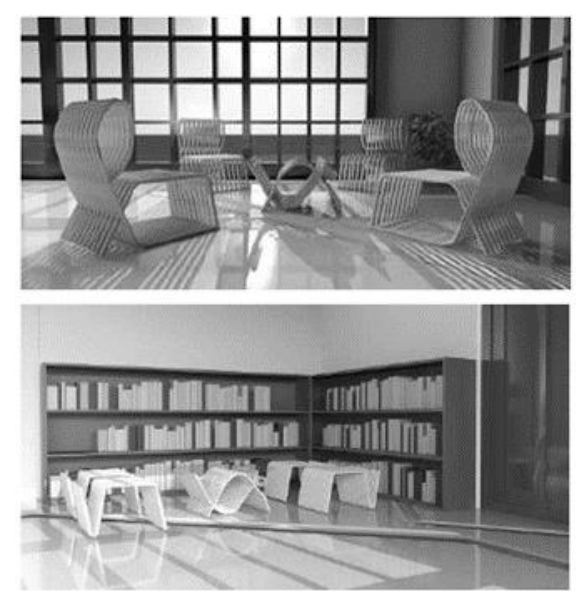

Konsep yang diambil dalam perancangan meja ini yaitu berasal dari budaya tari saman. Bentukan meja terinspirasi dari gerakan tari saman. Gerakan tari saman pada saat ditarikan terdiri atas beberapa gerakan, seperti gerakan menyilangkan tangan, gerakan bergandengan tangan, gerakan mengatup tangan dan juga gerakan meyilangkan tangan di bawah. Namun dalam furnitur set ini masih kurang dapat meminimalisir space dalam penggunaan ruang. Hal ini di karenakan desain yang memakan space sehingga tidak dapat di aplikasikan dalam ruangan sempit.

\section{PEMBAHASAN}

Tahapan studi analisa meliputi permasalahan-permasalahan yang ada pada bangunan komersial cafe saat ini:

1. Studi dan analisa denah / layout cafe: diperlukan sebagai acuan batasan dimensi furnitur.

2. Analisa Aktifitas: diperlukan sebagai acuan kebutuhan yang diperlukan pada furnitur. 
3. Analisa Dimensi Antropometri: diperlukan sebagai acuan pertimbangan dimensi yang standar.

4. Analisa Pasar: untuk mengidentifikasi peluang target pasar dari penelitian ini.

5. Analisa Trend: diperlukan sebagai acuan konsep trend yang disesuaikan dengan tren furnitur 2014 yaitu kontemporer.

6. Analisa Material: diperlukan sebagai pertimbangan pemilihan material yang sesuai dengan kebutuhan funiture

\section{Konsep Perancangan}

Konsep untuk meja kursi set ini adalah rowung, yaitu rotan dan kawung. Kawung sendiri berasal dari batik kawung, desain Menggunakan bentukan batik kawung, Batik ini berpola bulatan yang serupa dengan buah kawung yang ditata rapi secara geometris. Untuk kamu yang belum tahu apa itu buah kawung, yakni sejenis buah kelapa, yang terkadang juga dianggap sebagai buah kolang-kaling. Kemudian desain di gabung dengan bahan besi untuk memperkuat ketahanan produk agar maksimal dalam penggunaan nya. Berikut gambaran skematik desain.
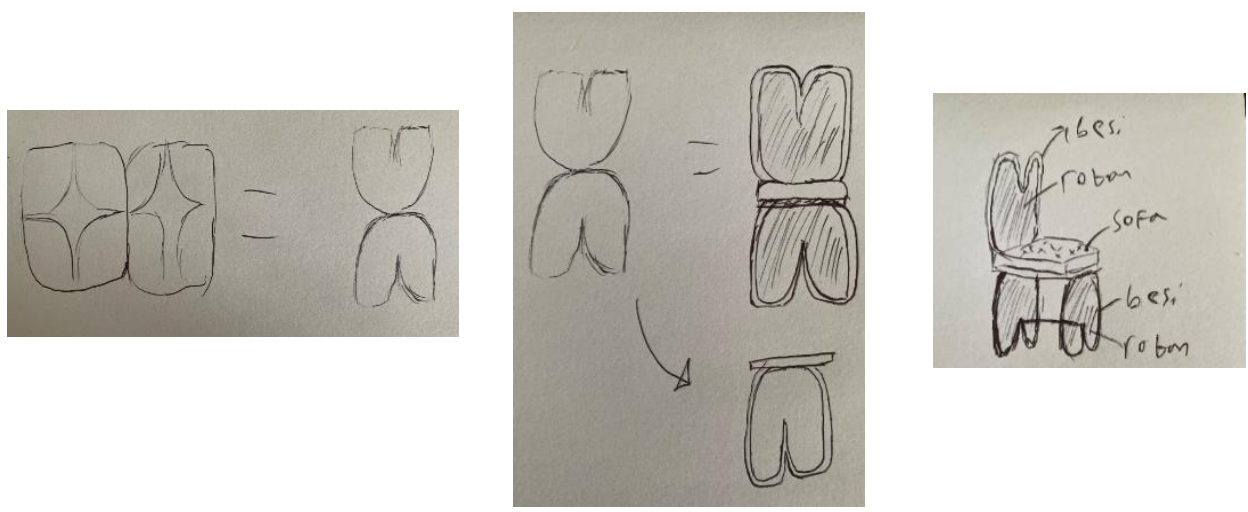

Setelah melalui proses skematik desain, desain kemudian masuk pada proses pengembangan desain. Desain di kembangkan agar kualitas produk dapat di maksimalkan dengan baik. Selain itu desain harus memenuhi aturan antopometri untuk dapat memberikan rasa nyaman pada pengguna produk. Untuk warna masih memanfaatkan motif rotan sehingga desain lebih terlihat sederhana dan unik karena material rotan. Berikut hasil akhir desain.

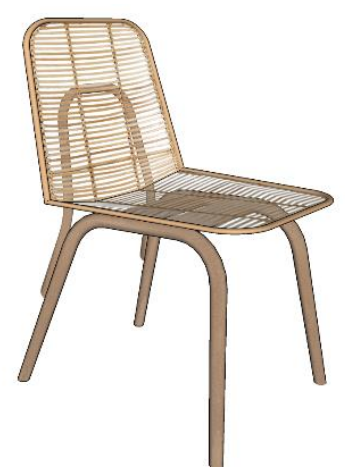



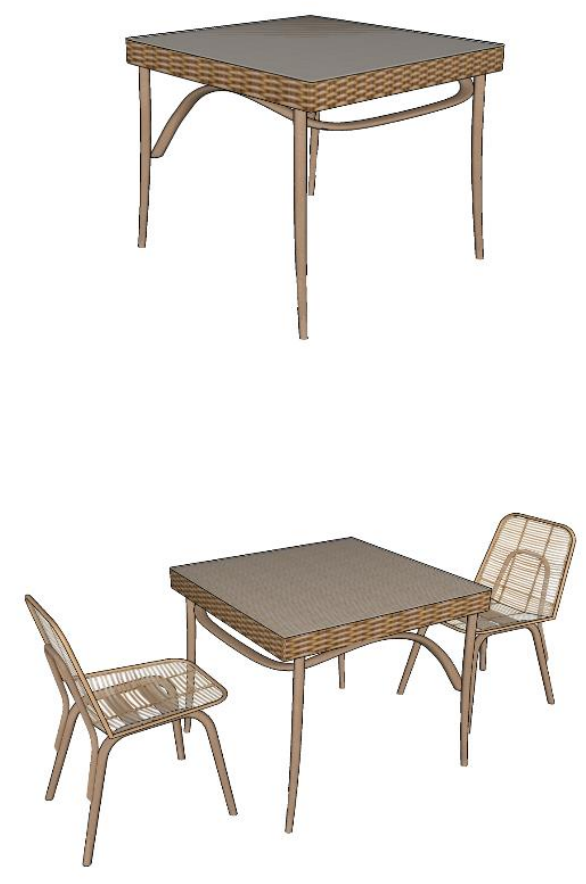

\section{KESIMPULAN}

Perancangan produk interior untuk cafe ini dapat mencapai tujuan sebagai berikut:

1. Memberikan inspirasi pada masyarakat bahwa material rotan mempunyai peluang yang baik sebagai pengganti kayu.

2. Memberikan solusi furnitur set yang simpel dan tidak memakan banyak sumber daya

3. Memberikan inspirasi produk dengan konsep budaya

\section{DAFTAR PUSTAKA}

Isjava, Membuat Custom Furnitur untuk Ruang Anda Menjadi Lebih Menarik , diakses dari, https://bildeco.com/blog/isjava-membuat-custom-furnitur-untuk-ruang-anda-menjadi-lebihmenarik/Pada tanggal 5 oktober 2020

http://rotanindonesia.yolasite.com/pustaka-rotan.php di akses pada tanggal 6 oktober 2020

Marlina, Endy. (2008). Panduan Perencangan Bangunan Komersil. Yogyakarta: Penerbit ANDI.

Panero, Julius and Zelnik Martin. (1979). Human Dimension \& Interior Space. New York: Whitney Library of Design 
Onesimus Bonar Naibaho ${ }^{1}$, Andereas Pandu Setiawan ${ }^{2}$

Produk Interior Modular Berbasis Budaya Nusantara dengan Memanfaatkan Materila Rotan untuk Cafe 